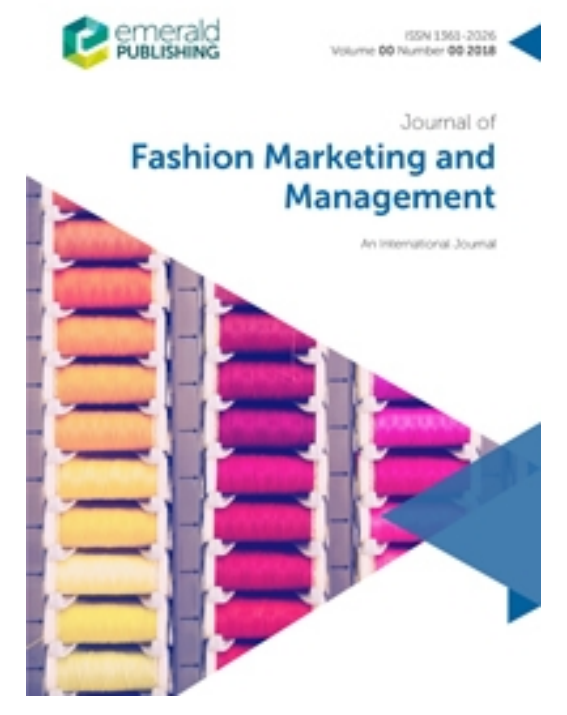

\title{
Who are social media influencers for luxury fashion consumption of the Chinese Gen Z? Categorisation and empirical examination
}

\begin{tabular}{|r|l|}
\hline Journal: & Journal of Fashion Marketing and Management \\
\hline Manuscript ID & JFMM-07-2020-0132.R1 \\
\hline Manuscript Type: & Original Article \\
\hline Keywords: & $\begin{array}{l}\text { Social Media Influencer, Luxury fashion, Social networks theory, Guanxi, } \\
\text { Social connectedness, Network interactivity }\end{array}$ \\
\hline Authors: & Yan Sun, Rachel Wang, Dongmei Cao, Rouyi Lee \\
\hline
\end{tabular}




\title{
Who are social media influencers for luxury fashion consumption of the Chinese Gen Z? \\ Categorisation and empirical examination
}

\begin{abstract}
Purpose - Social media influencers (SMIs) play an increasingly important role in influencing youth and their shopping behaviours in digital marketing. Research has examined various but fragmented SMIs, which cause inconsistency in empirical results. This research seeks to categorise the most popular SMIs in luxury fashion and examine their distinctive effects on Gen $\mathrm{Z}$ consumption in China. Design/methodology/approach - We categorise SMIs into four groups based on two dimensions, i.e. network interactivity versus social connectedness. Drawing on the social network theory, we develop the research model. A sample of 400 survey data is collected and analysed using the PLS-SEM technique.

Findings - The empirical results suggest that among the four popular SMIs groups, the effects of celebrities, opinion leaders, and friends and peers on luxury fashion consumption of Gen $\mathrm{Z}$ are statistically significant while that of advertisers are insignificant; that friends and peers have the most substantial effect among the others.

Origin/value - The study contributes to understanding SMIs and consumer behaviour in digital emerging markets. By categorising SMIs, this study reconciles inconsistencies in the concept. This study contributes to a better understanding of SMIs and their roles in the digital marketing of luxury fashion consumption.
\end{abstract}

Keywords: Social Media Influencer; Luxury fashion; Social networks theory; Guanxi; Social connectedness; Network interactivity 


\section{Introduction}

China has made up one-third of global luxury consumption (Bu et al., 2017). Bain and Co (2018) predicted that Chinese consumers would contribute RMB 1 trillion (approx. $£ 0.11$ trillion) in global luxury sales by 2025. With the ease of the Covid-19 lockdown measures in China, people return to boutiques and shopping malls, and revenge /rebound spending is expected to drive and lift the global luxury industry to grow again (William and Hong, 2020). Considering the already substantial market size and the increasing surging consumption power, no one wonders that the Chinese market will continue and become even more appealing to the global fashion luxury retails. However, not all international brands, including non-luxury brands, enjoy success in China. Tesco, the latest example of failure, has completely withdrawn from the Chinese market after a bumpy journey since the day of its launch (Hopkins, 2015). We argue in this research that understanding this emerging and the attractive market is one of the critical reasons for the success or failure of luxury fashion businesses in this emerging but lucrative market.

Moreover, with technological advancement, digital marketing and online sales have gradually overtaken the traditional ones since the 1990s and became mainstream (Alves et al., 2016; Arrigo, 2018; Huang et al., 2018). Social media platforms play a critical role in the retail trend and influence consumption behaviour (Akar et al., 2015; Cao et al., 2021). For instance, WeChat, the all-in-one social media platform in China, has 900 million users daily. The average time spent on WeChat among millions of users is about 70 minutes per day (Statista, 2018). As suggested by Bain and Co (2018), Luxury consumption will be $100 \%$ influenced by online interaction by 2025 . In this context, luxury brands and retailers are more than eager to understand the digital footprints of luxury consumers and particularly of social media influence in shaping the global luxury market.

The extant literature has suggested that social media platforms affect consumers' engagement behaviours (Geissinger and Laurell, 2016; Lim et al., 2019; Cao et al., 2021) and that social media influencers (SMIs) are significantly related to consumption behaviour (Shephard et al., 2016; Nam and 
Dan, 2018). Who, however, are the SMIs for luxury fashion consumption in the Chinese market? Literature has suggested various SMIs and their different roles influencing consumption behaviours, focusing on celebrity endorsement (e.g. Park and Yang, 2012; Knoll and Matthes, 2017; Wang et al., 2017; Jin and Ryu, 2019). Research suggests that family, peers, and opinion leaders have a significant effect on purchase intention. However, the role of these other SMIs has been underexplored though studied in a few limited publications (e.g. Vernette, 2004; Brandão et al., 2019). Moreover, different SMIs may influence consumer behaviour differently (Biswas et al., 2006). There is little understanding of who the SMIs are and their various effects on consumer behaviour, particularly in the context of the emerging and fast-developing luxury fashion market in China. This research aims to categorise SMIs and empirically examine their effects on the luxury fashion consumption of Chinese Gen Z. Born in 1995 and afterwards, Gen Z is digital natives who are extensively engaged towards technology (MacKenzie, and McGuire, 2016; Wiedmer, 2015) and also a target segment by SMIs marking (Lin et al., 2019).

Gen Z forms a significant force for luxury goods (Lee, 2018; WARC, 2018). According to Salleh et al. (2017), Gen $\mathrm{Z}$ are hypertext, overprotected, and tend towards instant gratification. Roesler (2015) reported that 47 per cent of millennials are influenced in their purchases by social media, compared to 19 per cent for all other age groups (Roesler, 2015). Furthermore, 70 per cent of Gen $\mathrm{Z}$ in China are willing to purchase from social media (Lee, 2018; Jourdan and Master, 2018), indicating that it is crucial to investigate Gen Z's purchase intention in luxury products from the social media perspective. However, Gen Z's consumption behaviour in the luxury sector remains under-researched. Deng and Chen (2018) suggested that Gen Z in China would prefer domestic brands compared to foreign brands, which is a sharp contrast to the old generation. In other words, repeating existing strategies and campaigns are not the best strategy for luxury brands to attract Gen Z in China (Lee, 2018). Therefore, this study explores how SMIs determine Chinese Gen Z's purchase decisions for luxury fashion consumption. 
For the remainder of the paper, we categorise SMIs and develop hypotheses in the following literature review. Then, we introduce the research methods and design. Further, we report and analyse the statistical results. Discussion of the findings and conclusions of our contributions are in the end.

\section{Literature Review}

\subsection{Social networks theory}

Social network theory explains the patterns of interactions and exchanges experienced by individuals in a society or community (Borgatti and Foster, 2003). A social network is defined as 'the collection of all the formal and informal social ties to which an actor is connected' (Che et al., 2018). An individual's position in a social network is reflected by his or her engagement activities and social connectedness with others in society (Mirkovski et al., 2018).

Developed further by the popularity of social media, social networks are also built to connect individuals in the current digital era to strengthen communications among users and impact online purchase (Jin and Ryu, 2019). Social networking sites (SNSs help make purchase decisions, including finding accurate information on the digital platforms and reducing their shopping risks), and advertisements on the SNSs show a significant positive impact on shopping behaviours (Yan et al., 2019). During the Covid-19 pandemic in 2020, the retailing landscape worldwide has been changed dramatically overnight. The traditional retail channel (physical stores) is no longer an option for individual consumers during the lockdown in various countries while shopping on digital platforms becomes 'new normal' for global consumers. Social media sites rapidly become the touchpoint for digital marketers to reach and interact with individual consumers (Ryan et al., 2017). SMIs are more active and prominently affect online consumption, particularly in the Guanxi networking society in China. 


\subsection{Guanxi society and social networks theory}

'Guanxi' refers to the unique Chinese network first introduced in sociological studies around the late 1970s, which describes relationships between people and connections built via traditional interactions among individuals (Hofstede, 1980). It is widely recognised that Guanxi drives the fundamental dynamic of social networks in Chinese society and communities. For instance, it is believed that people are relationship-oriented in nature and circles (large or small) are created from both personal and professional perspectives. Fan (2020a; 2020b) suggested three types: family guanxi, intra-organisational Guanxi, and extra-organisational Guanxi.

Strongly influenced by Confucian culture since ancient times, Guanxi still plays an essential role in cultivating relationships among individuals and between organisations in China today (Guo et al. 2018). Compared to the rule-based western societies, China is well known as a guanxi-based society, and interpersonal trust between individuals even offers an informal but effective way to deal with business transactions (Zhao and Vinig, 2019; Shareef et al., 2020). Guanxi acts as a medium to support network building and strengthen connection development in the business environment in China, for instance, to gather business information or opportunities.

Hofstede (1980) maintained a high degree of collectivism is one of the critical aspects of Chinese culture. Furthermore, Guanxi is a cultural phenomenon reflecting an individual's normal life in China and influences business strategy and practices, including a necessary procedure to establish an intention to complete business transactions (Chung and Hamilton, 2001). Yang (2019) explained that Guanxi among individuals could be improved by information sharing and greatly enhance online purchase intention. For instance, to maintain a good Guanxi with others, individuals would follow their friends and peers in the social media communities and show their support by positively responding to the posted content and timely forwarding the recommendation of purchases to others.

Guanxi successfully expands from the physical world to the virtual environment in the current digital age and is effectively applied in the e-business context. For instance, Guanxi plays an essential 
role in the crowdfunding sector in China and encourages online trust in business communities (Zhao and Vinig, 2019).

\subsection{Categorisation of SMIs}

Over the last decade, social media has become increasingly popular in digital marketing, such as engaging consumers (Cao et al., 2021) and promoting brands and influencing the purchase intention among individual consumers (Delbaere et al., 2020;). SMIs are individuals who actively create content (e.g. texts, images and videos) and regularly posts their views on their preferred social media channels; their posts are quickly consumed and followed by large social media audiences. Olanrewaju et al. (2020) suggested that the social status achieved by SMIs is used for business networking, information search and crowdfunding for their business.

The concept of SMI has been discussed in existing literature with a different focus (Jin and Phua, 2014). The latest illustration is proposed as 'individuals who gained popularity on the social media platform and a position of influence on their audience' in the general marketing context (Delbaere et al., 2020). However, this definition does not help understand the SMIs in a specific sector such as fashion luxury consumption in this study. Furthermore, little attention has been drawn to the 'categorisation of SMIs' under the context of luxury fashion and the young generation in emerging markets.

Marketing professionals in business sectors widely quote types of SMIs. As suggested by Kaya (2018), Grin (2020), Gulberti (2019) and Boyd (2016), types of SMIs such as Micro-Influencers (10K-100K), Mid-Tier Influencers (100K-500K), Mega Influencers (500K-2M), and All-Star Influencers $(+2 \mathrm{M})$ are set up using numbers of followers. However, using such types of SMIs lacks support from the academic literature and empirical test results. The strength of the influence maintained by types of SMIs remains unknown, and the degree of the interaction between individuals and SMIs is largely underexplored. 
From the existing literature, we identify four popular groups of SMIs, who through their social media activities, can influence consumers' purchase intention. Firstly, advertiser SMIs of luxury brands and their online interactivities can influence purchase behaviour (Phan et al., 2011; Duffett, 2017). Many studies have shared similar views of the impact of social media advertising on purchase intention (Powers et al., 2012; Wang and Qiao, 2020). Secondly, opinion leaders and their engagement on social media have been noted as an influential force on consumer behaviour in a few studies such as Vernette (2004), Wiedmann and Hennings (2013), and Brandão et al. (2019). Thirdly, friends and peers have considerable influences on one's purchase intention and behaviour (Rajput and Kanna, 2014). Consumers trust content from their friends and peers more than any other form of marketing communication (Dennhardt, 2014; Mo and Wong, 2019; Singh et al., 2020). Lastly, messages that delivered by celebrities receive more attention and make a stronger impression than those messages transmitted without celebrity endorsement (Kahle and Homer, 1985; Knoll and Matthes, 2017). Consumers tend to transfer their perception towards the celebrity to the product being endorsed. Thus, the acceptability of brands will increase as they trust the celebrity (Biswas et al., 2006; Li et al., 2019). Therefore, this study investigates how these four groups of SMIs influence Chinese Gen Z's purchase decision in luxury products (Figure 1).

The four groups of SMIs can be distinguished based on two dimensions: social connectedness and network interactivity. Social connectedness refers to the extent of a close relationship in society. The magnitude of the social connectedness is reflected by the number of 'friends' and 'contacts' on the social media page (Sedera et al., 2019). A Facebook user has 338 friends on average, and 15\% of the users have more than 500 friends (Smith, 2019). WeChat, the dominating social media tool in China, reposts 1 billion daily active users, and an average user has 194 contacts on WeChat (Iqbal, 2020).

The connectedness via social media has brought the original definition of social connectedness (as the experience of belonging to a social relationship or network) to digital connectedness. Social connectedness provides individuals with a "so-real" virtual environment to minimise physical 
interactions (Daft and Lengel, 1986; Sedera et al., 2019). As proposed in Figure 1, 'Friends and peers' shows closer connectedness among four factors influencing luxury consumption in young consumers in China. 'Opinion leader' is in the second place of 'social connectedness' while 'Celebrity' is in the third place, which has more influence than 'Advertiser'.

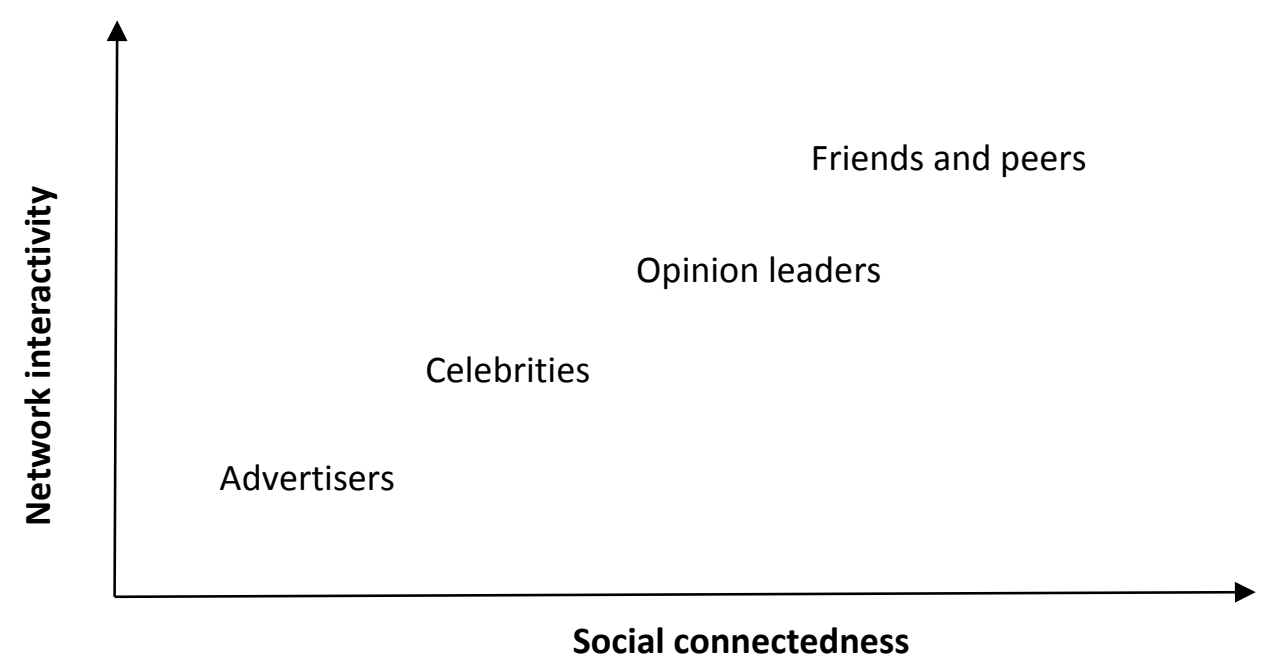

Figure 1. Categorisation of SMIs

Interactivity has been defined from various perspectives in previous literature. For instance, Zhao and Lu (2012) explained 'interactivity' through mobile responsiveness among users, and Lee (2005) suggested 'interactivity' as a multidimensional construct in the digital context. Alalwan et al. (2020) validated the role of 'interactivity' from the customer's perspective under digital technology and mobile shopping.

Network interactivity is defined as the extent of network interactions in this study. On social media brand communities, luxury brands provide immediate, interactive and low-cost communication with their youth customers through SMIs (Arrigo, 2018). Among the four proposed groups of SMIs in Figure 1, 'Friend and peer' presents the most dynamic network interactivity. Individuals can act as influencers to influence each other on information adoption and decision-making daily, such as choosing a holiday destination, making a purchase on specific products and services, or catching up with the latest political and social issues (Lin and Huang, 2018). 


\subsection{Hypotheses and research model}

According to Bovee (1992) and Todorova (2015), the advertisers' role is to develop impersonal marketing communication about a product and service through different media. The five fundamental purposes of advertising are to grab attention/raise interest, develop and sustain interest, create desire, incite action, and create goodwill (Shahid, 1999). The marketing communication of a luxury brand should be able to distinguish it from a non-luxury brand. For instance, luxury brands must strictly follow their brand identity so that consumers can differentiate the brand from other non-luxury brands (Bastien and Kapferer, 2012). Fionda and Moore (2009) found that luxury products or brands are more likely to use a fashion show and other similar events in marketing communication. In this case, advertising of luxury products or brands are not made to sell but to 'keep the dream alive' via customer engagement.

It is to believe that effective advertising can strengthen luxury product purchase intention among consumers as well-articulated advertising can minimise the product risk by providing sufficient information and highlighting the essential attributes of the products (Khan et al., 2017). In mainland China, advertising undoubtedly plays a vital role in creating brand meaning. Notably, social media advertising becomes a widely used tool to encourage communication between luxury brands and potential customers (Wang and Qiao, 2020).

Although many studies have investigated the influence of advertisers on consumers purchase intention, very little literature has focused on the effect of advertisers on Chinese Gen Z's purchase intention of luxury goods,

H1. Advertises/advertisements through social media significantly influence Chinese Gen Z's purchase decision concerning luxury goods.

Compared to non-luxury brands, luxury brands took a relatively slow approach to social media while many brands are still carefully exploring the benefits from social networks. Encouraged by the positive results of 'use of Facebook' among retailers, the burning question for luxury brands now 
becomes how to present themselves online instead of whether to move to the virtual environment (Brandão et al., 2019).

Inevitably, social media influencer has grown to be an essential marketing tool for many organisations to promote their products and reach consumers (Jaakonmaki et al., 2017; Sudha and Sheena (2017). Opinion leaders inhabit a place between celebrities (less approachable) and friends and peers (more approachable), and they build a closer relationship with the audience through regular interaction and share of interests (Dhanani, 2017). For instance, personal experience, product reviews, photos and videos are shared and exchanged between influencers and followers almost in real-time via a social media platform.

One of the key elements contributing to the emergence of opinion leaders is interaction (Uzunoglu and Kip, 2014). The interaction with online users or fans significantly impacts their purchase intention as consumers can directly contact the content creators (Alves et al., 2016). In the United States, 70\% of millennials trust and relate to opinion leaders more than celebrities as they bond with them from shared interest, daily interaction, and responses to the content they created that aren't possible with traditional celebrities (Burgess, 2017). On the other hand, the theory of conspicuous consumption maintains that luxury brands are projecting one's wealth and social status. Luxury fashion consumption provides ego-enhancing benefits, and opinion leaders usually set up a level of social status that consumers would like to achieve. Hence, this affects consumers' purchase intentions as they purchase luxury goods to obtain a social situation like the opinion leaders (Sivanathan and Pettit, 2010).

The trend of influential marketing continues to grow recently. It becomes an extension to wordof-mouth marketing focusing on social context and operating more professionally. Furthermore, it is a form of relationship and trust built between the content creator and their audience, which can be beneficial for brands to improve business awareness and customer loyalty (Sudha and Sheena, 2017). For example, Bughin (2015) found that approximately 50 per cent of first-time buyers were more likely to be influenced by the recommendation from opinion leaders. Sudha and Sheena (2017) indicated that 
blogs could significantly impact young women purchase intention after reading a positive review of a product. Nam and Dan (2018) also showed that opinion leaders have a tremendous impact on consumer purchase intention in Ho Chi Minh City, Vietnam. Hence, we propose Hypothesis 2 as follows.

H2. Opinion leaders through social media activities significantly influence Chinese Gen Z's purchase intention of luxury goods.

Iyengar et al. (2009) suggested that friends and peers might influence the purchase decisions of an individual under a social network setting. Wu et al. (2015) also investigated whether the information exchange concerning luxury products was an enjoyable communication between friends and peers. Interestingly, Eom and Seock (2015) found that Western female consumers are less affected by peers than Asian consumers and that brand image and media influences are the main determinants of luxury consumption in mature markets. However, in Chinese society, the social setting among friends and peers serves as the primary influence on purchasing luxury products (Wang and Qiao, 2020). Peer reference significantly impacts purchase decisions involving luxury fashion brands (Zhang and Kim, 2013).

Individuals from collectivist cultures, for instance, China, tend to emphasise the goals of the whole group and remains interdependent among group members (Mo and Wong, 2019). In Chinese society, people need to make a serious commitment to be accepted as one part of the social class or reference group (Phau and Prendergast, 2001, Hung et al., 2011). Catching up with friends and peers in the social context is the reason to explain luxury purchase in general, which is to secure one's position in a social group by following the same consumption trend (Husic and Cicic, 2009).

Previous studies showed that friends and peers have a significant impact on consumers' purchase intention. The more likely the peer pressure exists, the more likely they will follow their friends and peers to buy a particular brand or product (Akar et al., 2015; Gulati, 2017). Hence, marketers take advantage of this phenomenon by providing incentives related to the pressure from friends and peers, such as coupons or discounts offering the purchase of identical products with friends and peers (Chang 
and Nguyen, 2018). However, very little evidence is found to support whether this impact between friends and peers would still affect social media. Therefore, it is worthwhile to investigate how friends and peers could influence Chinese Gen Z's purchasing intention of luxury goods via social media and to propose that,

H3. Friends and peers through social media activities influence Gen Z's purchase intention of luxury goods.

Celebrities are the individuals who are known to the public, such as actors, supermodels, pop singers, athletes, and others of the line for their achievement in various areas (Friedman and Friedman, 1979). Marketers frequently use them to endorse products, services, ideas and organisations (Ohanian, 1991). The physical attractiveness of celebrities can influence the consumers' perception of a brand and enhance the promotional effect (Kahle and Homer, 1985). Park and Yang (2010) also found that celebrity conformity had a positive impact on the purchase intention of the celebrity-endorsed brand.

The expanded investigation has been conducted by adding the celebrities' personality, likability, experience, and credibility (Abbas et al., 2018). According to Wang et al. (2017), the celebrity's credibility is an essential factor in enhancing consumers' brand attitude, credibility, and purchase intention. Ahmed et al. (2014) also proved that the higher the endorser's credibility, the better result can be achieved in stimulating consumers' purchase intention. Therefore, using an attractive celebrity with high credibility and related experience to promote products is the golden rule for companies to seize market share and increase revenues.

In China, celebrities represent traditional values and social norms. Consumers feel more secure and confident by imitating celebrities' dressing style (Hung et al., 2011). In terms of 'individual access to resources in a society, celebrities usually are in an advantageous position which reflects 'the character of exclusivity of luxury ( $\mathrm{Li}$ et al. 2019). This creates opportunities for luxury retailers in China to emphasise their products or brands as a celebrity's favourite or utilise well-known individuals as brand ambassadors. Besides, celebrities also act as role models where consumers are inclined to 
follow the brands endorsed by their favourite celebrities (Ahmed et al., 2014). This is mainly a common phenomenon in China, where people claimed that dressing in the latest fashion as celebrities and showing similar tastes helps to gain self-esteem and self-confidence.

Ghaffar et al. (2017) also reported that celebrity endorsement, directly and indirectly, affects consumer purchase intention. The empirical result concluded by Tan et al. (2013) also indicated that celebrity endorsement has a significant and positive relationship with the purchase intention of the luxury brand. Therefore, we propose that celebrity endorsement in social media sites would influence Chinese Gen Z's purchasing intention towards luxury goods.

H4. Celebrities through social media activities influence Chinese Gen Z's purchase intention of luxury goods.

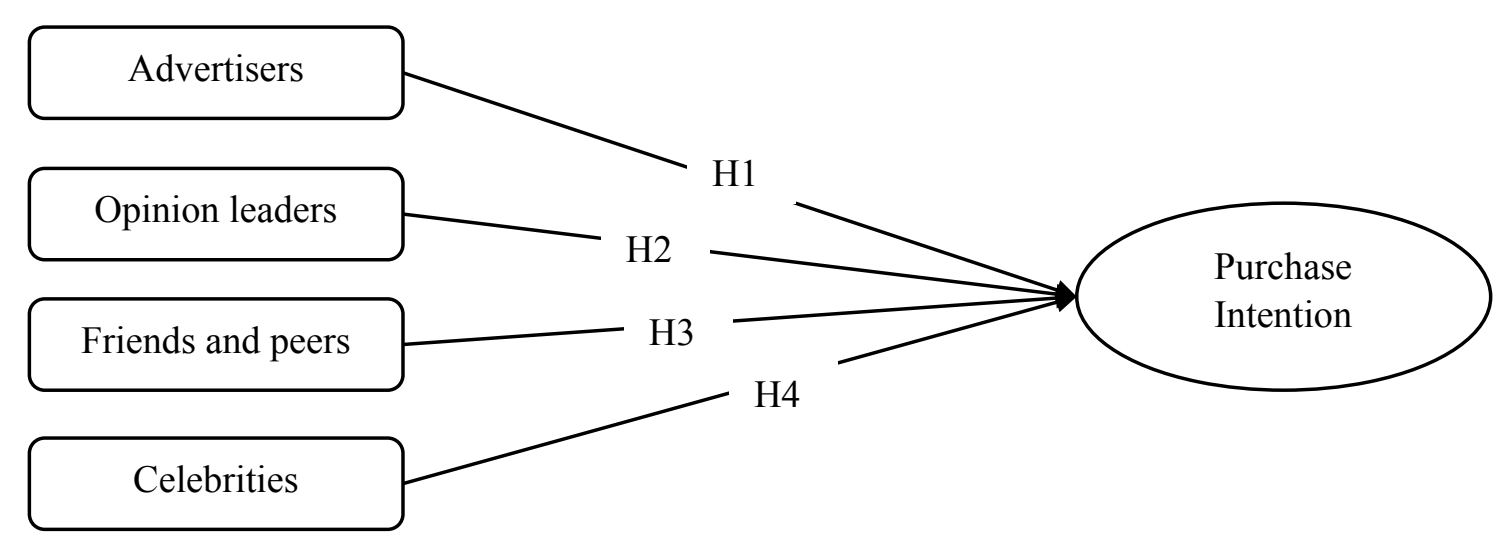

Figure 2. Research model

As a summary, the research model depicting the hypotheses under investigation is presented in Figure 2. Hofstede (2018) suggested that China has a surprisingly low level of indulgence and high luxury consumption. This puzzle can be explained from the Guanxi culture and the social networks theory in previous literature, suggesting the SMIs as the main motives behind luxury purchase among Chinese consumers (Zhang and Kim, 2013; Xie, 2014; Gao and Jia, 2014). 


\section{Research Methodology}

\subsection{Measures}

A questionnaire was designed for the primary data collection for this study. Part one of the questionnaire was concerned with participants' demographic information, including age, gender, education, income and occupation. Part two asked participants about their behaviour and opinions regarding advertisers, opinion leaders, friends and peers, and celebrities related to their purchase behaviours. Three items measuring advertiser influence were adapted from Nazeer (2017). Opinion leader influence was measured by three items adapted from Sudha and Sheena (2017). We adopted four items measuring friend and peer influence from Wang et al. (2012). Celebrity influence was measured by five items, adapted from Wang et al. (2017). Measurement items of purchase intention were adapted from Brandão et al. (2019). Except for Part one, participants were required to answer the questions on a five-point Likert scale from strongly disagree (as '1'), disagree (as '2'), neutral (as '3'), and agree (as '4') to strongly agree (as '4').

\subsection{Sampling and data}

The target sample for this study is the Generation $\mathrm{Z}$ of Chinese Nationals who consume luxury products. The sample was selected using convenience and snowball methods. The social media platforms WeChat and Weibo, and emails were used for the questionnaire data collection. We sent out 1844 survey requests and a sample of 400 valid responses collated for this study. The sample size is sufficient to support the intended research and statistical tests (Tabachnick et al., 2019).

All respondents fell into Generation $\mathrm{Z}$ with ages ranging from 18 to 24 in 2019, among whom 53.3 per cent are between 18-20 years old, and 46.8 per cent are between 21-23 years old. The sample is composed of 47.8 per cent males and 52.3 per cent females. Among all respondents, twelve per cent completed a secondary and below education, 36.8 per cent completed diploma education, and 51.2 per cent achieved a degree and above education level. About 12 per cent of respondents' annual income is lower than the national average disposable income (National Bureau of Statistics, 2019) and more than 
55 per cent respondents' yearly income is more than 100,000 RMB, suggesting that most of the respondents have the financial capacity to purchase luxury products. As a result, the analysis of the respondents' age, gender, education and income status confirm that they are an appropriate sample for this study.

PLS-SEM (partial least squares and structural equation modelling) was utilised for the data analysis. First of all, SEM analyses structural relationships between latent constructs, which is one of the fundamental reasons for its popularity in social science studies (Richter et al., 2016; Cao et al., 2021). Secondly, PLS-SEM selected for this study was due to its advantages, such as capacity (Hair et al., 2014) and flexibility to introduce new latent variables and explore new relationships to an established theory (Ringle et al., 2015; Richter et al., 2016; Cao et al., 2021). Furthermore, compared to the covariance-based SEM method, PLS-SEM has more functional advantages, for example, a lower sample size requirement (Hair et al., 2014) and ease to apply to solve complex relationships such as mediation and moderation models (Richter et al., 2016; Cao et al., 2021). Therefore, PLS-SEM was judged to be an appropriate choice for this study.

\section{Statistical Results}

This section presents the analytical results, including the descriptive statistics, the reliability and validity of the constructs, and the results of the structural model and hypotheses testing.

\subsection{Descriptive statistics}

Table 1 reports descriptive statistics, including the mean and standard deviation of the sample. The means of all items range from 3.59 to 3.78 . The result of the means suggests that the respondents, in general, chose 'agree' or 'strongly agree' with the statements in the questionnaire, indicating the items examined are well relevant to this study.

Table 1. Descriptive statistics: Means and Standard Deviations

\begin{tabular}{ll}
\hline Advertisers & Mean/ S.D. \\
\hline I often view advertisements for luxury products on social media. & $3.69 / 1.18$ \\
\hline
\end{tabular}




\subsection{Construct reliability and validity}

Before the factor analysis, a normality test was conducted to examine whether the issues of normality are evident in the study. The results are shown in Table 2. The skewness values range from -.663 to -.782 , and the Kurtosis values between 0.199 to 0.758 align with the acceptable range of \pm 1 . The results confirm that there is no significant issue of normality in the study.

Table 2. Results of Normality Tests

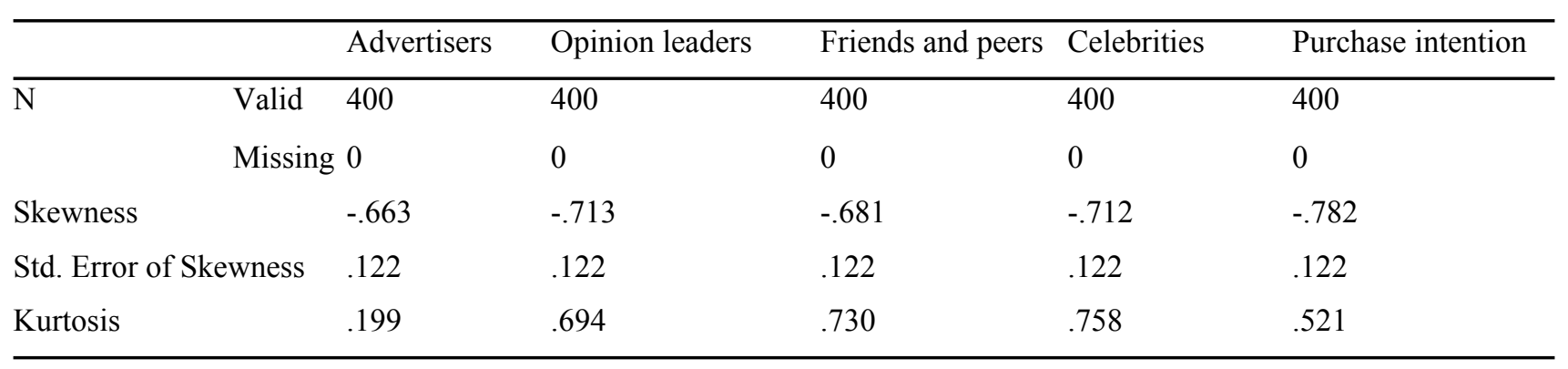




\begin{tabular}{llllll}
\hline Std. Error of Kurtosis & .243 & .243 & .243 & .243 & .243 \\
\hline
\end{tabular}

PLS algorithm was performed for factor analysis using Smart PLS 3.0. Table 3 presents the results for construct reliability and validity testing. All outer loadings, ranging from 0.949 to 0.987 , are above the threshold value of 0.70. All Cronbach's Alpha (CA) values ranging from 0.972 to 0.988 and Composite Reliability (CR) values ranging from 0.982 to 0.991 are above the threshold value of 0.70 , indicating that satisfactory consistency and reliability are achieved. All Average Variance Extracted (AVE) scores range from 0.946 to 0.954 , suggesting the internal convergent validity of the constructs.

Table 3. Measurement assessment: Outer loadings, Construct reliability and validity

\begin{tabular}{|c|c|c|c|c|c|}
\hline Indicator & Advertisers & Celebrities & Friends and peers & Purchase intention & Opinion leaders \\
\hline Ad1 & 0.983 & & & & \\
\hline $\mathrm{Ad} 2$ & 0.987 & & & & \\
\hline Ad3 & 0.949 & & & & \\
\hline CI1 & & 0.984 & & & \\
\hline $\mathrm{CI} 2$ & & 0.976 & & & \\
\hline $\mathrm{CI} 3$ & & 0.980 & & & \\
\hline CI4 & & 0.965 & & & \\
\hline CI5 & & 0.980 & & & \\
\hline Fr1 & & & 0.973 & & \\
\hline Fr2 & & & 0.970 & & \\
\hline Fr3 & & & 0.981 & & \\
\hline Fr4 & & & 0.968 & & \\
\hline PI1 & & & & 0.964 & \\
\hline PI2 & & & & 0.983 & \\
\hline PI3 & & & & 0.977 & \\
\hline PI4 & & & & 0.980 & \\
\hline OL1 & & & & & 0.984 \\
\hline OL2 & & & & & 0.977 \\
\hline OL3 & & & & & 0.962 \\
\hline AVE & 0.947 & 0.954 & 0.946 & 0.953 & 0.949 \\
\hline $\mathrm{CR}$ & 0.982 & 0.991 & 0.986 & 0.988 & 0.982 \\
\hline $\mathrm{CA}$ & 0.972 & 0.988 & 0.981 & 0.983 & 0.973 \\
\hline
\end{tabular}


Discriminant validity of the constructs was verified using the Heterotrait-Monotrait (HTMT) Ratio Criterion. As presented in Table 4, all HTMT values (off-diagonal), ranging from 0.374 to 0.615 , are lower than the suggested HTMT 0.85 criterion (Ringle et al., 2015). Therefore, the discriminant validity of the constructs was established.

Table 4. Discriminant validity: Heterotrait-Monotrait (HTMT) Ratio

\begin{tabular}{|c|c|c|c|c|c|}
\hline & 1 & 2 & 3 & 4 & 5 \\
\hline 1 Advertisers & 0.973 & & & & \\
\hline 2 Celebrities & $\begin{array}{r}0.40 \\
9\end{array}$ & 0.977 & & & \\
\hline 3 Friends and peers & $\begin{array}{r}0.48 \\
1\end{array}$ & $\begin{array}{r}0.45 \\
4\end{array}$ & 0.973 & & \\
\hline 4 Opinion leaders & $\begin{array}{r}0.51 \\
9\end{array}$ & $\begin{array}{r}0.49 \\
8\end{array}$ & $\begin{array}{r}0.37 \\
4\end{array}$ & 0.974 & \\
\hline 5 Purchase intention & $\begin{array}{r}0.46 \\
2\end{array}$ & $\begin{array}{r}0.52 \\
3\end{array}$ & $\begin{array}{r}0.61 \\
5\end{array}$ & $\begin{array}{r}0.46 \\
2\end{array}$ & 0.976 \\
\hline
\end{tabular}

Note: The diagonal displays the square root of the average variance extracted (AVE) in bold.

\subsection{Model and hypotheses testing}

The structural relationships and the model fit were then examined. Table 5 presents the algorithm and bootstrapping tests results, including the effect sizes of coefficient $\beta$, the corresponding significance of the effects of T values and $\rho$ values and conclusions of support for each hypothesis.

The results suggest that advertising is insignificantly related to Gen Z's intention to purchase luxury products, e.g. Advertisers $->$ Purchase intention $(\beta=0.098, \rho<0.1)$. This finding does not support H1.

Celebrity is significantly related to Gen Z's intention to purchase luxury products with a small-tomedium-size effect, e.g. Celebrities $\rightarrow$ Purchase intention $(\beta=0.223, \rho<0.001)$. This finding supports H2. Friends and peer are significantly related to Gen Z's purchase intention in luxury products with a medium-size effect, e.g. Friends and peers -> Purchasing intention $(\beta=0.407, \rho<0.001)$. This finding supports H3. Opinion leaders are significantly related to Gen Z's purchase intention in luxury 
products with a small-size effect, e.g. Opinion leaders $->$ Purchasing intention $(\beta=0.146, \rho<0.01)$. This finding supports H4.

Table 5 and Figure 3 also presents the model fit indicators, including SRMR (0.025), Chi-square (2,310.11), NFI (0.912). The R square value (0.472) indicates that the model and the independent variables explain Gen Z's purchase intention under investigation and that SMIs, including celebrities, friends and peers, and opinion leaders are the significant determinants for the Chinese Gen Z's luxury fashion consumption behaviour.

Table 5. Results of algorithm and bootstrapping tests

\begin{tabular}{|c|c|c|c|c|c|c|}
\hline & Coefficients & Mean & $\begin{array}{l}\text { Standard } \\
\text { Deviation }\end{array}$ & $\begin{array}{c}\mathrm{T} \\
\text { Statistics }\end{array}$ & $\begin{array}{c}\mathrm{P} \\
\text { Values* }\end{array}$ & $\begin{array}{c}\text { Suppor } \\
\mathrm{t}\end{array}$ \\
\hline Advertisers -> Purchase intention & 0.098 & 0.096 & 0.054 & 1.855 & 0.064 & No \\
\hline Celebrities -> Purchase intention & 0.223 & 0.224 & 0.054 & 4.058 & 0.000 & Yes \\
\hline $\begin{array}{l}\text { Friends and peers }->\text { Purchase } \\
\text { intention }\end{array}$ & 0.407 & 0.407 & 0.054 & 7.539 & 0.000 & Yes \\
\hline $\begin{array}{l}\text { Opinion leaders }->\text { Purchase } \\
\text { intention }\end{array}$ & 0.146 & 0.145 & 0.052 & 2.760 & 0.006 & Yes \\
\hline
\end{tabular}

Note: $* \mathrm{p}<0.05$ (two-tailed)

Figure 3 further depicts the algorithm results produced by the SmartPLS3 software. 


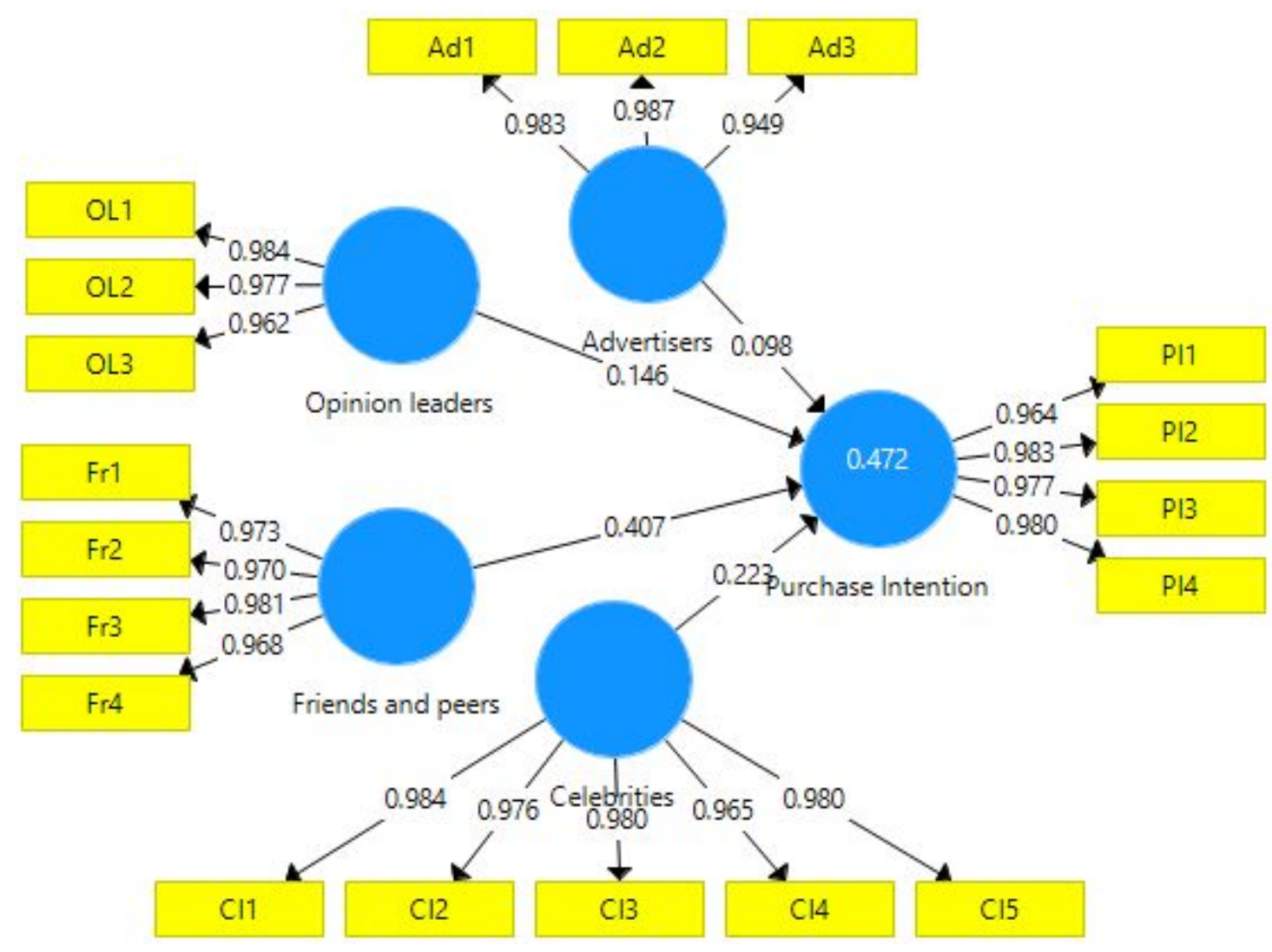

Figure 3. SmartPLS Algorism results

\section{Discussion}

Four hypotheses investigating the impact of SMIs on Chinese Gen Z's purchase intention in luxury products have been tested in this study.

Firstly, our results suggest that there is no evidence to support the effect of advertisers on social media sites on Chinese Gen Z's purchase intention in luxury fashion products. This result does not align with existing studies on advertisements' impact on consumers' purchase behaviour (Powers et al., 2012; Nazeer, 2017). Traditional ads can stimulate consumers' rational perception of the brand by formulating brand equity (Keller, 2001) and maintaining a desire and dream among the audience to own luxury products or brands (Kapferer and Bastien, 2009). However, this study reveals that advertiser among the four SMIs has the most negligible effects. This result is perhaps primarily due to the limited network interactivity and accessibility with the customers, which causes dysfunction in Gen Z consumers' emotional connections and motivation. Although consumers are exposed to a 
considerable amount of information and advertising message every day, it has become critical for social media marketers to engage and build up a relationship with individual consumers online actively (Kang and Kim, 2017). Instead of relying on advertiser on traditional media, the advantage of social media is that it is convenient and can reach an extensive coverage of audience with little costs (Phan et al., 2011).

Secondly, the results confirm that opinion leaders are significantly and positively related to Chinese Gen Z's purchase intention in luxury fashion products. This result is different from the existing study by Kennedy and Bolat (2017), which concludes that given opinion leaders are being paid to post favourable reviews on social media, there is a reduced trust from consumers and consequently decreased influences over consumers' purchase intention. With the prevalence of social media in consumers' daily activities, retailers have recognised the increased importance of opinion leaders reaching their target market (Jaakonmaki et al., 2017). In line with the existing research on the credibility of opinion leaders (Burgess, 2017), this study further indicates that social connectedness and network interactivity between opinion leaders and consumers consequently positively impact the purchase intention in luxury fashion products.

Thirdly, the results confirm that the influence of friends and peers is the strongest of all four SMIs on Chinese Gen Z's purchase intention in luxury fashion products. This result agrees with the findings from Iyengar et al. (2009), which suggests consumers' intention to match the behaviour and status of their friends and peers in the same social network. The result supports the study by Wu et al. (2015), which suggests that Chinese are prone to display their status among their friends and peers and enjoy communicating about their experience with luxury products within their social networks. Moreover, among the four factors under investigation, the influence of friends and peers demonstrates the most influential impact on their purchase intention. This result is in line with the existing study by Dennhardt (2014), who argued that the trust the consumer's place in their friends and peers makes it the most influential factor in all of the variables. Considering that China is a collectivist society and 
highly relationship-based, luxury fashion promotions shall examine the influence of friends and peers on social media, so their friends and peers who follow their feed will be made aware of the brand. They will tend to follow due to their need to be included by their social network.

Fourthly, the results confirm that celebrity endorsement is positively significant in Chinese Gen Z's purchase intention in luxury products. This result agrees with some existing studies (Kahle and Homer, 1985; Biswas et al., 2006; Wu et al., 2015), confirming celebrities' influence on consumers' purchase intention. Considering that the Chinese place high importance on their 'face' Guanxi culture, it is recommended that luxury brands not only use celebrities but also change their celebrity ambassadors periodically, so the brand can capture a different range of target markets and help convert more consumers to purchase their products. The opportunity to own something recognised by their favourite celebrities will also help the Chinese consumers achieve their self-actualisation needs, particularly when they are being placed at the same social class as these celebrities who are highly respected by society.

As a result, the proposed four popular and distinctive SMIs and their effects provide the theoretical implications that social connectedness and network interactivity can adequately explain and predict Chinese Gen Z's purchase intention of luxury fashion in medial social marketing. We are aware that these theoretical propositions need more empirical examinations in the future.

\section{Conclusion}

Through a sample of 400 Chinese Gen $\mathrm{Z}$ respondents, this study finds that the four SMIs play different roles in influencing Chinese Gen Z's purchase intention of luxury fashion. Opinion leaders, friends and peers, and celebrities significantly influence purchase intention, while there is no evidence to support the role of advertisers. Also, Friends and peers have the most substantial effect; opinion leaders are the next strongest SMIs; celebrities have a significant but most minor impact compared to the others. The underpinning theory could be that social connectedness and network interactivities explain the different relationships. The stronger the social connectedness and the more network interactivities, 
there will be the more positive and more substantial effect on Chinese Gen Z's purchase intention of luxury fashion.

There are limitations in our study which provide potentials for the future research direction. One of the limitations is the conceptualisation of SMIs. We have developed two dimensions for the categorisation of SMIs, which are network interactivity and social connectedness. However, we have not directly examined the conceptual relationships. Therefore, the findings in the current study make it possible to conceptualise SMIs and empirically examine the more conceptual relationships of SMIs in the future. Second, the findings in this study are related to the Chinese Gen Z's purchase intention associated with their social media engagement. Therefore, caution should be taken while applying the findings to general contexts. Third, the challenges and concerns related to social media content must also affect Gen Z's purchase intention. This dark side of digital social media marketing could be another future research. 


\section{References}

Abbas, A., Afshan, G. and Khan, S. B. (2018), "The effect of celebrity endorsement on customer purchase intention: A comparative study predictors and consequences of human resource outsourcing view project internal marketing view project", Current Economics and Management Research, Vol. 4 No. 1, pp. 1-10.

Ahmed, N., Farooq, O. and Iqbal, J. (2014), "Credibility of celebrity endorsement and buying Intentions: an evidence from students of Islamabad, Pakistan", International Letters of Social and Humanistic Sciences, Vol. 20, pp. 1-13.

Akar, E., Yüksel, H. F. and Bulut, Z. A. (2015), "The impact of social influence on the decision-making process of sports consumers on Facebook", Journal of Internet Applications and Management, Vol. 6 No. 2, pp. 5-27.

Alalwan, A. A., Algharabat, R. S., Baabdullah, A. M., Rana, N. P., Qasem, Z. and Dwivedi, Y. K. (2020), "Examining the impact of mobile interactivity on customer engagement in the context of mobile shopping", Journal of Enterprise Information Management, Vol. 33 No. 3, pp. 627-653.

Alves, H., Fernandes, C. and Raposo, M. (2016), "Social media marketing: A literature review and implications", Psychology and Marketing, Vol. 33 No. 12, pp. 1029-1038.

Arrigo, E. (2018), "Social media marketing in luxury brands: A systematic literature review and implications for management research", Management Research Review, Vol. 41 No. 6, pp. 657679.

Bain and Co. (2018), China is the Key for a Rosy Global Luxury Market Outlook: Bain \& Co., available at: https://jingdaily.com/china-bain/ (accessed 7 Dec 2018).

Bastien, V. and Kapferer, J. N. (2012), "Luxe Oblige", 2nd ed., Paris, Groupe Eyrolles.

Biswas, D., Biswas, A. and Das, N. (2006), "The differential effects of celebrity and expert endorsements on consumer risk perceptions: The role of consumer knowledge, perceived congruency, and product technology orientation", Journal of Advertising, Vol. 35 No. 2, pp. 17- 
31.

Borgatti, S. P. and Foster, P.C. (2003), "The network paradigm in organisational research: a review and typology", Journal of Management, Vol. 29 No. 6, pp. 991-1013.

Bovee, C. L. and Arens, W. F. (1992), "Contemporary advertising", 4th ed, Homewood, IL, Irwin.

Boyd, S. (2016), How Instagram Micro-Influencers Are Changing Your Mind One Sponsored Post at a Time, available at: https://www.forbes.com/sites/sboyd/2016/06/28/how-instagrammicro-influencers-are-changing-your-mind-one-sponsored-post-at-a-time/?sh=68e2c07034a1. (accessed 19 April 2021).

Brandão, A., Pinho, E. and Rodrigues, P. (2019), "Antecedents and consequences of luxury brand engagement in social media", Spanish Journal of Marketing - ESIC, Vol. 23 No. 2, pp. 163-183.

Bu, L., Durand-Servoingt, B., Kim, A. and Naomi, Y. (2017), Chinese luxury consumers: More global, more demanding, still spending, available at: https://www.mckinsey.com/businessfunctions/marketing-and-sales/our-insights/chinese-luxury-consumers-more-global-moredemanding-still-spending (accessed 1 Jul 2019)

Bughin, J. (2015), "Getting a sharper picture of social media" s influence", McKinsey Quarterly, Vol. 3, pp. 8-11.

Burgess, E. (2017), Social Media Creators Are More Influential than Celebrities, available at: https://www.ion.co/millennials-listen-social-media-creators-celebrities (accessed 08 Aug 2019) Cao, D., Meadows, M., Wong, D. and Xia S. (2021), "Understanding consumers' social media engagement behaviour: An examination of the moderation effect of social media context", Journal of Business Research, Vol. 122, pp. 835-846.

Chang, S. C. and Nguyen, T. A. (2018), "Peer pressure and its influence on consumers in Taiwan", African Journal of Business Management, Vol. 12 No. 8, pp. 221-230.

Che, Y., Li, Y., Fam, K.S. and Bai, X. (2018), "Buyer-seller relationship, sales effectiveness and sales revenue: a social network perspective", Nankai Business Review International, Vol. 9 No. 4, pp. 
414-436.

Chung, W.K. and Hamilton, G.G. (2001), "Social logic as business logic: Guanxi, trustworthiness, and the embeddedness of Chinese business practices", Rules and Networks: Theory and Practice, Vol. 39 No.1, pp.75-100.

Daft, R. L. and Lengel, R. H. (1986), "Organisational information requirements, media richness and structural design", Management Science, Vol. 32 No. 5, pp. 554-571.

Delbaere, M., Michael, B., Phillips, B.J. (2020), "Social media influencers: A route to brand engagement for their followers", Psychology Marketing. Vol. 38, pp. 101-112.

Dennhardt, S. (2014), User-generated content and its impact on branding: How users and communities create and manage brands in social media, Gabler Verlag, Wiesbaden.

Deng, I. and Chen, C. (2018), China's Generation Z prefer domestic names to foreign brands, report says, available at: https://www.scmp.com/tech/china-tech/article/2148316/anarchy-chinawealthy-generation-z-prefers-domestic-brands-over (Accessed 6 Feb 2018).

Dhanani, Z. (2017), Why social influencers outsell celebrities, available at: https://www.forbes.com/sites/forbescommunicationscouncil/2017/10/31/why-social-influencersoutsell-celebrities/\#48ef94c0425b (Accessed 5 Sep 2018).

Duffett, R. (2017), "Influence of social media marketing communications on young consumers' attitudes", Young Consumers, Vol.18 No. 1, pp.19-39.

Eom, H. J. and Seock, Y. K. (2015), "Factors influencing purchase intention toward luxury fashion brands", Proceedings of International Textile and Apparel Association, pp. 1-3.

Fan, Y. (2020a), "Guanxi's consequences: personal gains at social cost", Journal of Business Ethics, Vol.38 No4, pp.371-380.

Fan, Y. (2020b), "Questioning guanxi: definition, classification and implications", International Business Review, Vol.11 No.5, pp.543-561.

Friedman, H. H. and Friedman, L. (1979), "Endorser effectiveness by product type", Journal of 
Advertising Research, Vol. 19 No. 5, pp. 63-71.

Fionda, A. M. and Moore, C. M. (2009), "The anatomy of the luxury fashion brand", Journal of Brand Management, Vol. 16 No. 5-6, pp. 347-363.

Gao, Y. and Jia, M. (2014), An Insight Into Chinese Consumer Behavior In Home Furnishings Industry- A Quantitative Research On How "Mianzi" Factor Influence Chinese Consumers Behavior. available at: https://www.diva-portal.org/smash/get/diva2:761619/ FULLTEXT01.pdf. (Accessed 10 Nov 2018).

Geissinger, A. and Laurell, C. (2016), "User engagement in social media - an explorative study of Swedish fashion brands", Journal of Fashion Marketing and Management, Vol. 20 No. 2, 177190.

Ghaffar, S., Rashid, A., Nisa, Q. A., Rehman, S. U. and Abbas, A. (2017), "Does celebrity endorsement influence the consumer purchase intentions \& corporate image? Mediating role of advertising appeal", Conference of Business Management, pp. 1-11.

GRIN (2020), 10 Types of SMIs You Can Work With, available at: https://grin.co/blog/types-of-socialmedia-influencers/. (Accessed 25 Apr 2021).

Gulati, S. (2017), "Impact of peer pressure on buying behavior", International Journal of ResearchGranthaalayah, Vol. 5 No. 6, pp. 280-291.

Gulberti, G., (2019), Four types of Influencers and the brand objectives you can achieve with them, available at: https://www.launchmetrics.com/resources/blog/types-of-influencers. (Accessed 23 Aprił 2021)

Guo, W., Sun, S. and Dai, R. (2018), "Guanxi deviant behaviour in the Chinese cultural context", Qualitative Research in Organisations and Management: An International Journal, Vol. 13 No. 2, pp. 162-182.

Hair, J., Jr, Sarstedt, M., Hopkins, L. and Kuppelwieser, V. (2014), "Partial least squares structural equation modeling (PLS-SEM): An emerging tool in business research", European Business 
Review, Vol. 26 No. 2, 106-121.

Hofstede, G. (1980), "Culture's consequences: international differences in work-related values", Cross-Cultural Research, Vol.1.

Hofstede, G. (2018), What about China? available at: https:/www.hofstedeinsights.com/country/china/ (accessed 25 Apr 2020).

Hopkins, K. (2015), Tesco: failure to crack China lay in lack of understanding about market, available at: https://www.raconteur.net/business-innovation/why-tesco-failed-to-crack-china (Accessed 8 Dec 2018).

Huang, R., Ha, S. and Kim, S. H. (2018), "Narrative persuasion in social media: an empirical study of luxury brand advertising", Journal of Research in Interactive Marketing, Vol. 12 No. 3, pp. 274292.

Hung, K. P., Chen, A. H., Peng, N., Hackley, C., Tiwsakul, R. A. and Chou, C. L. (2011), "Antecedents of luxury brand purchase intention", Journal of Product and Brand Management, Vol. 20 No. 6, pp. 457-467.

Husic, M. and Cicic, M. (2009), "Luxury consumption factors", Journal of Fashion Marketing and Management, Vol. 13 No. 2, pp. 231-245.

Iqbal, M. (2020), WeChat revenue and usage statistics, available at: https://www.businessofapps.com/data/wechat-statistics/ (accessed 1 Jul 2019).

Iyengar, R., Han, S. and Gupta, S. (2009), "Do Friends Influence Purchases in a Social Network? ", Harvard Business Review, No. 09-123.

Jaakonmaki, R., Muller, O. and von Brocke, J. (2017), "The impact of content, context and creator on user engagement in social media marketing", Proceedings of the 50th Hawaii International Conference on System Sciences (HICSS), 50, pp. 1152-1160.

Jin, S. and Ryu, E. (2019), "Celebrity fashion brand endorsement in Facebook viral marketing and social commerce", Journal of Fashion Marketing and Management, Vol. 23 No. 1, pp. 104-123. 
Jin, S. and Phua, J. (2014), "Following celebrities' tweets about brands: The impact of twitter-based electronic word-of-mouth on consumers' source credibility perception, buying intention, and social identification with celebrities", Journal of Advertising, Vol. 43 No. 2, pp.181-195.

Jourdan, A. and Master, F. (2018), China's young shoppers breathe new life into luxury market, available at: https://www.reuters.com/article/us-china-luxury/chinas-young-shoppersbreathe-new-life-into-luxury-market-idUSKBN1FK0YT (Accessed: 5 May 2018).

Kahle, L. R. and Homer, P. M. (1985), "Physical attractiveness of the celebrity endorser: A social adaptation perspective", Journal of Consumer Research, Vol. 11 No. 4, pp. 954-954.

Kang, J. and Kim, J. (2017), "Online customer relationship marketing tactics through social media and perceived customer retention orientation of the green retailer", Journal of Fashion Marketing and Management, Vol. 21 No. 3, 298-316.

Kapferer, J. N. and Bastien, V. (2009), "The specificity of luxury management: Turning marketing upside down", Journal of Brand Management, Vol. 16 No. 5-6, pp. 311-322.

Kaya, I.K. (2018), Social Media Influencers: Mega, Macro, Micro or Nano, available at: https://www.cmswire.com/digital-marketing/social-media-influencers-mega-macro-micro-or-

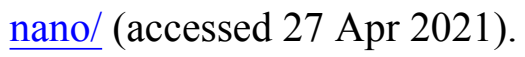

Keller, K.L. (2001), "Building customer-based brand equity: A blueprint for creating strong brands", Marketing Science Institute, Cambridge, MA.

Kennedy, G. and Bolat, E. (2017), Meet the HENRYs: a hybrid focus group study of conspicuous luxury consumption in the social media context - competitive paper, available at: http://eprints.bournemouth.ac.uk/29423/3/AM17 0335 competitive.pdf. (Accessed 08 Oct 2018).

Khan, N. J., Razzaque, M. A. and Hazrul, N. M. (2017), "Intention of and commitment towards purchasing luxury products: A study of Muslim consumers in Malaysia", Journal of Islamic Marketing, Vol. 8 No. 3, pp. 476-495.

Knoll, J. and Matthes, J. (2017), "The effectiveness of celebrity endorsements: a meta-analysis", 
Journal of the Academy of Marketing Science, Vol. 45 No. 1, pp. 55-75.

Lee, C. (2018), "Wise up: The big mistakes luxury brands are making with China's Gen Z",- Jing Daily, 28 May 2018.

Lee, T. (2005), "The impact of perceptions of interactivity on customer trust and transaction intentions in mobile commerce", Journal of Electronic Commerce Research, Vol.6, No.3, pp.165-180.

Li, J., Guo, S., Zhang, J. Z. and Sun, L. (2019), "When others show off my brand: self-brand association and conspicuous consumption", Asia Pacific Journal of Marketing and Logistics, Vol. 32 No. 6, pp. 1214-1225.

Lim, H., Cho, M. and Bedford, S. (2019), "You Shall (Not) Fear: The effects of emotional stimuli in social media campaigns and moral disengagement on apparel consumers' behavioral engagement", Journal of Fashion Marketing and Management, Vol. 23 No. 4, pp. 628-644.

Lin, X. and Huang, H. (2018), "When guanxi meets connectivity: The underlying mechanisms of young adults" participation in micro-charity", Journal of Information, Communication and Ethics in Society, Vol. 16 No. 1, pp. 32-44.

Lin, M-H, Vijayalakshmi, A. and Laczniak, R. (2019), "Toward an Understanding of Parental Views and Actions on Social Media Influencers Targeted at Adolescents: The Roles of Parents' Social Media Use and Empowerment", Frontiers in Psychology, Vol. 10, pp. 2664-2664.

MacKenzie, J. and McGuire, R. (2016), The First Generation of the Twenty-First Century, available at:

https://static1.squarespace.com/static/56d7388222482e1e2c87c683/t/56e0cdc2cf80a1468467019 4/1457573327672/MagidPluralistGenerationWhitepaper.pdf (accessed 20 May 2018).

Mirkovski, K., Jia, Y., Liu, L. and Chen, K. (2018), "Understanding microblogging continuance intention: The direct social network perspective", Information Technology \& People, Vol. 31 No. 1, pp. 215-238.

Mo, T. and Wong, N. (2019), "Standing out vs fitting in: luxury value perception and acculturation", 
International Marketing Review, Vol. 36 No. 3, pp. 483-510.

Nam, L. G. and Dân, H. T. (2018), "Impact of social media Influencer marketing on consumer at Ho Chi Minh City", The International Journal of Social Sciences and Humanities Invention, Vol. 5 No. 5, pp. 4710-4714.

National Bureau of Statistics (2020), Residents' income and consumption expenditure in 2019, available at: http://www.stats.gov.cn/tjsj/zxfb/202001/t20200117 1723396.html (accessed $25 \mathrm{Apr}$ 2020).

Nazeer, J. (2017), "Impact of social media advertisements on university students", Arts Social Science Journal, Vol. 8 No. 4, available at: https://www.hilarispublisher.com/open-access/impact-of$\underline{\text { social-media-advertisements-on-universitystudents-2151-6200-1000290.pdf }}$

Ohanian, R. (1991), "The impact of celebrity spokespersons' perceived image on consumers' intention to purchase", Journal of Advertising Research, Vol. 31 No. 1, pp. 46-54.

Olanrewaju, A.S.T., Hossain, M. A., Whiteside, N. and Mercieca, P. (2020), "Social media and entrepreneurship research: A literature review", International Journal of Information Management, Vol. 50, pp. 90-110.

Park, S. Y. and Yang, Y. (2012), "The effect of celebrity conformity on the purchase intention of celebrity sponsorship brand: The moderating effects of symbolic consumption and face-saving", Journal of Global Fashion Marketing, Vol. 1 No. 4, pp. 215-229.

Phan, M., Thomas, R. and Heine, K. (2011), "Social media and luxury brand management: The case of Burberry", Journal of Global Fashion Marketing, Vol. 2 No. 4, pp. 213-222.

Phau, I. and Prendergast, G. (2000), "Consuming luxury brands: The relevance of the 'Rarity Principle' ", Journal of Brand Management, Vol. 8 No. 2, pp. 122-138.

Powers, T., Advincula, D., Austin, M. S., Graiko, S. and Snyder, J. (2012), "Digital and social media in the purchase-decision process: A special report from the advertising research foundation", Journal of Advertising Research, Vol. 52 No. 4, pp. 479-489. 
Rajput, N. and Khanna, A. (2014), "Dynamics of young Indian consumers' ' buying behavior towards branded apparels: Gender perspective", Archives of Business Research, Vol. 2 No. 5, pp. 84-106.

Richter, N. F., Cepeda, G., Roldán, J. L. and Ringle, C. M. (2016), "European management research using partial least squares structural equation modeling (PLS-SEM) ", European Management Journal, Vol. 34 No. 6, pp. 589-597.

Ringle, C. M., Wende, S. and Becker, J. M. (2015), "SmartPLS 3", Boenningstedt, SmartPLS GmbH, available at: http://www.smartpls.com (accessed 20 Apr 2020)

Roesler, P. (2015), How social media influences consumer buying decisions, available at: https://www.bizjournals.com/bizjournals/how-to/marketing/2015/05/how-social-mediainfluences-consumer-buying.html (accessed 5 May 2018).

Ryan, T., Allen, K. A., Gray, D. L. and McInerney, D. M. (2017), "How Social are Social Media? A Review of Online Social Behaviour and Connectedness", Journal of Relationships Research, Vol. 8 No. e8, pp. 1-8. Advanced online publication. https://doi.org/10.1017/jrr.2017.13

Salleh, M., Mahbob, N. and Baharudin, N. (2017), "Overview of "Generation Z" Behavioral Characteristic and Its Effect towards Hostel Facility", International Journal of Real Estate Studies, Vol. 11 No. 2, pp. 59-67.

Sedera, D., Lokuge, S. and Perera, W. J. (2019), "How likely is your family to visit you? The effect of digital connectedness on intention to travel to Australia", Worldwide Hospitality and Tourism Themes, Vol. 11 No. 2, pp. 217-225.

Shahid, M. I. (1999), "Mass Communication", 2nd ed., Lahore, Carvan Press.

Shareef, M. A., Kapoor, K.K., Mukerji, B. and Diwivedi, R., (2020), "Group behavior in social media: Antecedents of initial trust formation", Computer in Human Behavior, Vol.105, pp. 106225.

Shephard, A., Pookulangara, S., Kinley, T. and Josiam, B. (2016), "Media influence, fashion, and shopping: A gender perspective", Journal of Fashion Marketing and Management, Vol. 20 No. 1, pp. 4-18. 
Singh, J., Crisafulli, B., Quamina, L.T. and Xue, M.T. (2020), "To trust or not to trust': The impact of SMIs on the reputation of corporate brands in crisis", Journal of Business Research, Vol. 119, pp. $\underline{464-480 .}$

Sivanathan, N. and Pettit, N. (2010), "Protecting the self through consumption: Status goods as affirmational commodities", Journal of Experimental Social Psychology, Vol. 46 No. 3, pp.

564-570.

Smith, K. (2019), 53 incredible Facebook statistics and Facts, available at: https://www.brandwatch.com/blog/facebook-statistics/ (accessed 1 Jul 2019).

Statista. (2018), Topic: Social Networks in China, available at: https://www.statista.com/topics/1170/social-networks-in-china/ (Accessed 8 Jan 2019).

Sudha, M. and Sheena, K. (2017), "Consumer decision process: Impact of influencers in the fashion industry", SCMS Journal of Indian Management, Vol. 93 No. 3, pp. 14-29.

Tabachnick, B. G. and Fidell, L. S. (2007), Using Multivariate Statistics, 7th ed. Pearson, Harlow.

Tan, M. Z., Teoh, S. Y., Tan, C. E., Teo, P. N. and Tan, M. K. (2013), "Perceived purchase intention of undergraduates towards luxury brands: case study", Proceeding of the International Conference on Social Science Research, pp. 735-746.

Todorova, G. (2015), "Marketing communication mix", Trakia Journal of Science, Vol. 13 No.1, pp. 368-374.

Uzunoglu, E. and Misci Kip, S. (2014), "Brand communication through digital influencers: Leveraging blogger engagement"", International Journal of Information Management, Vol. 34 No. 5, pp. 592602.

Vernette, É. (2004), "Targeting women's clothing fashion opinion leaders in media planning: An application for magazines", Journal of Advertising Research, Vol. 44 No. 1, pp. 90-106.

Wang, S., Kao, G. and Ngamsiriudom, W. (2017), "Consumers" attitude of endorser credibility, brand and intention with respect to celebrity endorsement of the airline sector", Journal of Air Transport 
Management, Vol. 60, pp. 10-17.

Wang, Y. and Qiao, F. (2020), "The symbolic meaning of luxury-lite fashion brands among younger

Chinese consumers", Journal of Fashion Marketing and Management, Vol. 24 No. 1, pp. 83-98.

Wang, X., Yu, C. and Wei, Y. (2012), "Social media, peer communication and impacts on purchase intentions: a consumer socialisation framework", Journal of Interactive Marketing, Vol. 26 No. 40, pp. 198-208.

WARC (2019), China's Gen $Z$ champion 'compression era', available at: https://www.warc.com/newsandopinion/news/chinas gen z champion compression era/40988 (Accessed 6 Dec 2018).

Wiedmann, K. P. and Hennigs, N. (2013), Luxury marketing: A challenge for theory and practice, Springer Gabler, Wiesbaden.

Wiedmer, T. (2015), "Generations do differ: Best practices in leading traditionalists, Boomers, and Generations X, Y, and Z", Delta Kappa Gamma Bulletin, Vol. 82 No. 1, pp. 51-51.

Williams, R. \& Hong, J. S. (2020), Revenge spending' spurs Chinese luxury rebound from virus, available at: https://www.bloomberg.com/news/articles/2020-03-12/luxury-shoppers-in-chinaemerge-from-quarantine-to-buy-again (accessed on 20 Apr 2020).

Wu, M. S. S., Chaney, I., Chen, C. H. S., Nguyen, B. and Melewar, T. C. (2015), "Luxury fashion brands: Factors influencing young female consumers' luxury fashion purchasing in Taiwan", Qualitative Market Research, Vol. 18 No. 3, pp. 298-319.

Xie, W. (2014), The Motivation of the Chinese tourists Buying Luxury Goods in Europe, available at: https://www.theseus.fi/bitstream/handle/10024/86708/Wan-Xie.pdf? sequence=1\&isAllowed=y.

(accessed 10 Dec 2018).

Yan, B., Chen, Y. R., Zhou, X. T. and Fang, J. (2019), "Consumer behavior in the omni-channel supply chain under social networking services", Industrial Management \& Data Systems, Vol. 119 No. 8, pp. 1785-1801. 
Yang, X. (2019), "Consumers' decisions in social commerce: the role of guanxi elements", Asia Pacific Journal of Marketing and Logistics, Vol. 31 No. 4, pp. 759-772.

Zhang, B. and Kim, J. H. (2013), "Luxury fashion consumption in China: Factors affecting attitude and purchase intent", Journal of Retailing and Consumer Services, Vol. 20 No. 1, pp. 68-79.

Zhao, L. and Vinig, T. (2019), "Guanxi, trust and reward-based crowdfunding success: a Chinese case", Chinese Management Studies, Vol. 14 No. 2, pp. 455-472.

Zhao, L. and Lu, Y. (2012), "Enhancing perceived interactivity through network externalities: an empirical study on micro-blogging service satisfaction and continuance intention", Decision Support System, Vol.53 No.4, pp.825-834. 


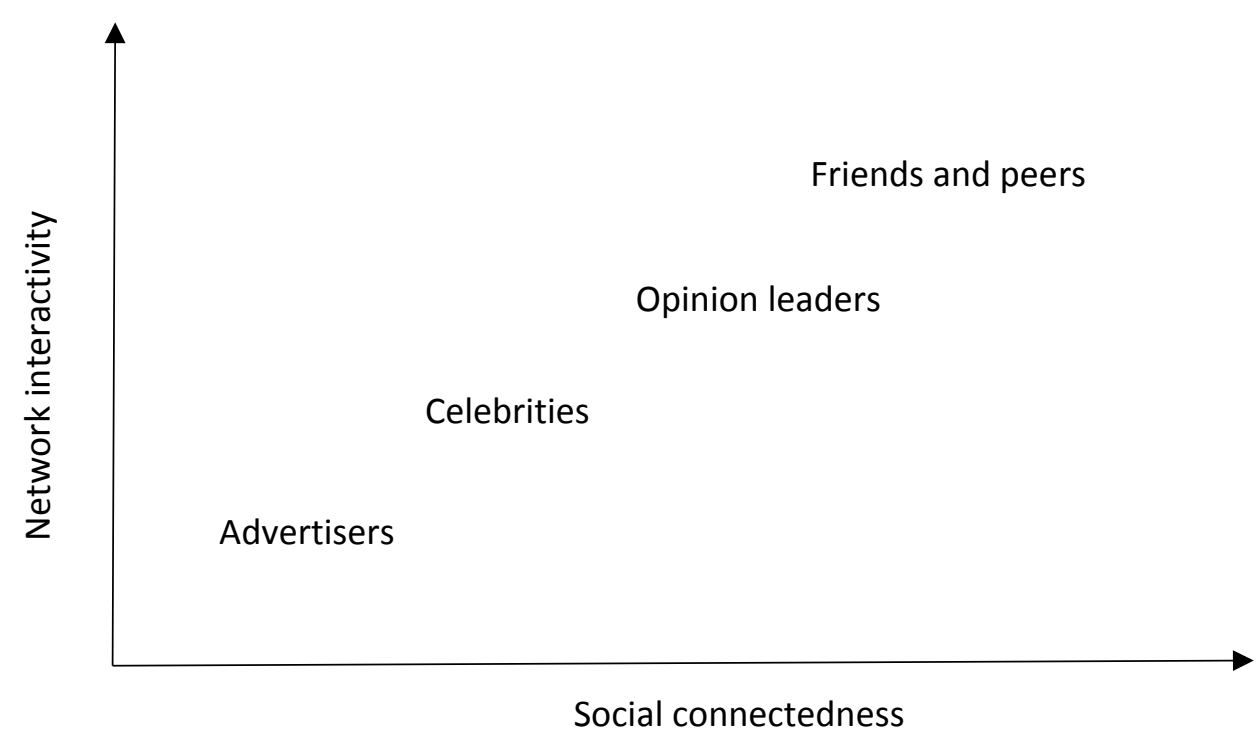

Figure 1. Categorisation of SMIs

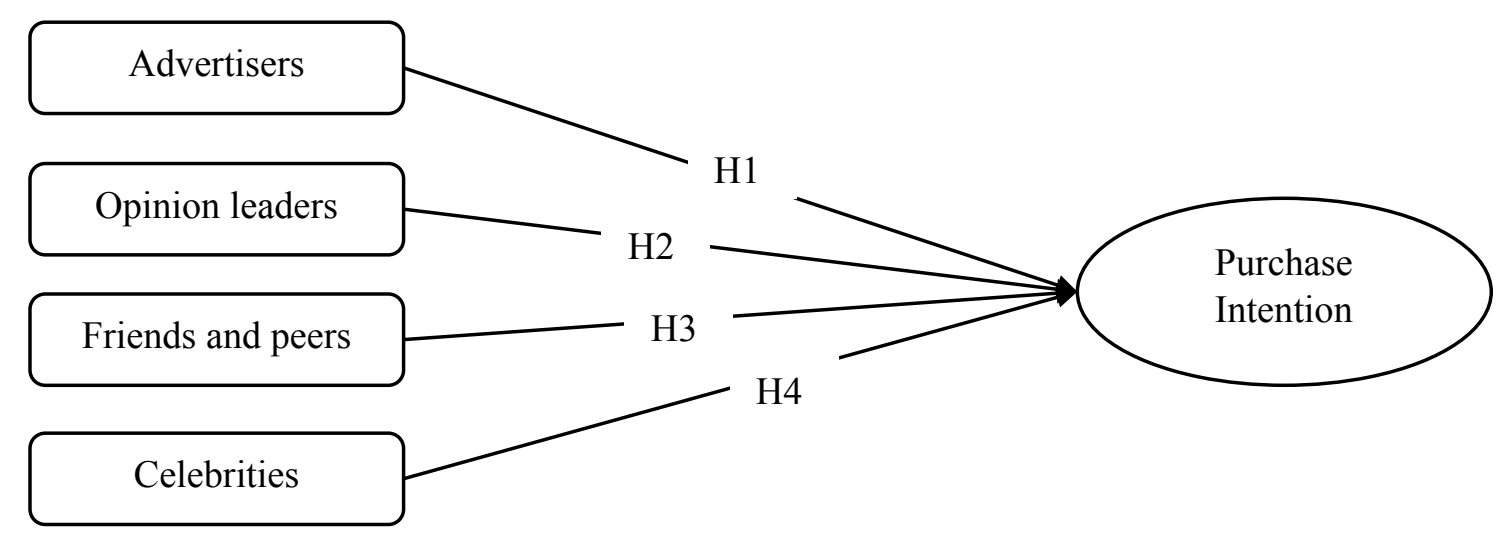

Figure 2. Research model 


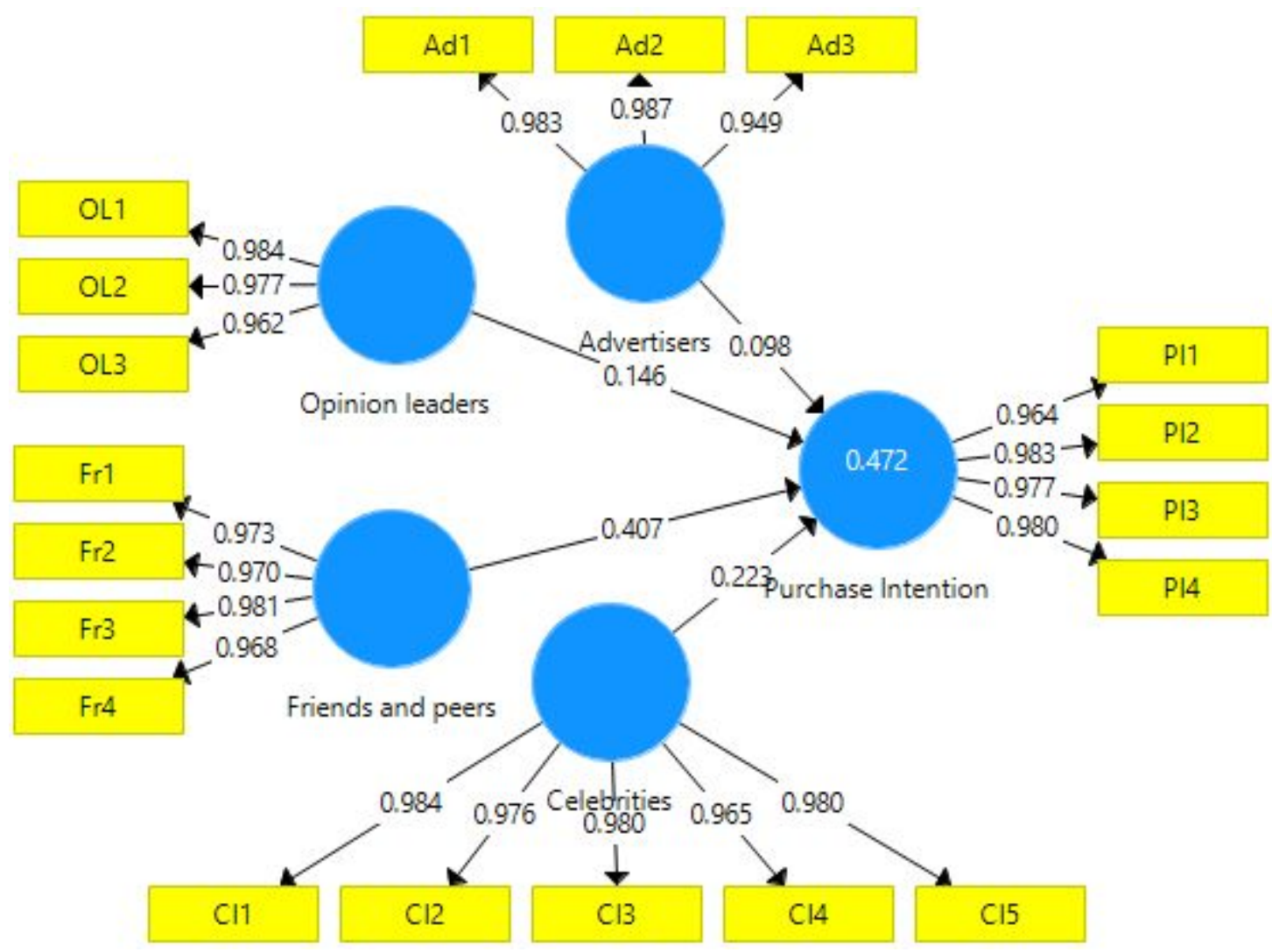

Figure 3. SmartPLS Algorism results 
Table 1. Descriptive statistics: Means and Standard Deviations

\begin{tabular}{ll}
\hline Advertisers & Mean/ S.D. \\
\hline I often view advertisements for luxury products on social media. & $3.69 / 1.18$ \\
Social media advertisements can influence my behaviour. & $3.71 / 1.14$ \\
I often visit social media advertisement pages of luxury products & $3.75 / 1.13$ \\
Opinion leaders & \\
I often follow posts and videos by opinion leaders & $3.61 / 1.18$ \\
My fashion choice, for instance, selection of luxury, is to a degree influenced by opinion leaders. & $3.65 / 1.13$ \\
I like to dress like an opinion leader I like. & $3.59 / 1.23$ \\
Friends and peers & \\
My friends often recommend some luxury products for me. & $3.66 / 1.17$ \\
I often follow posts and videos of luxury products by friends. & $3.69 / 1.12$ \\
My fashion choice, for instance, selection of luxury, is to some degree influenced by friends. & $3.65 / 1.15$ \\
Friends play a role in my purchasing behaviour of the luxury product. & $3.64 / 1.21$ \\
Celebrities & \\
I often follow social media posts and videos of a luxury product by celebrities. & $3.73 / 1.17$ \\
I often purchase a luxury product recommended on social media by celebrities & $3.71 / 1.19$ \\
My fashion choice, for instance, selection of luxury is to some degree influenced by celebrities & $3.72 / 1.16$ \\
I like to dress like a social celebrity I like. & $3.78 / 1.09$ \\
Celebrities play a role in my purchasing behaviour of the luxury product. & $3.72 / 1.17$ \\
Purchase intention & \\
I would choose a luxury product recommended by social media friends and peers. & $3.73 / 1.15$ \\
I would be influenced by social media advertisement & $3.75 / 1.12$ \\
Social media chat influences my purchase decision. & $3.75 / 1.14$ \\
I often refer to people in social media when making a luxury purchase decision. & $3.71 / 1.14$ \\
\hline
\end{tabular}

Table 2. Results of Normality Tests

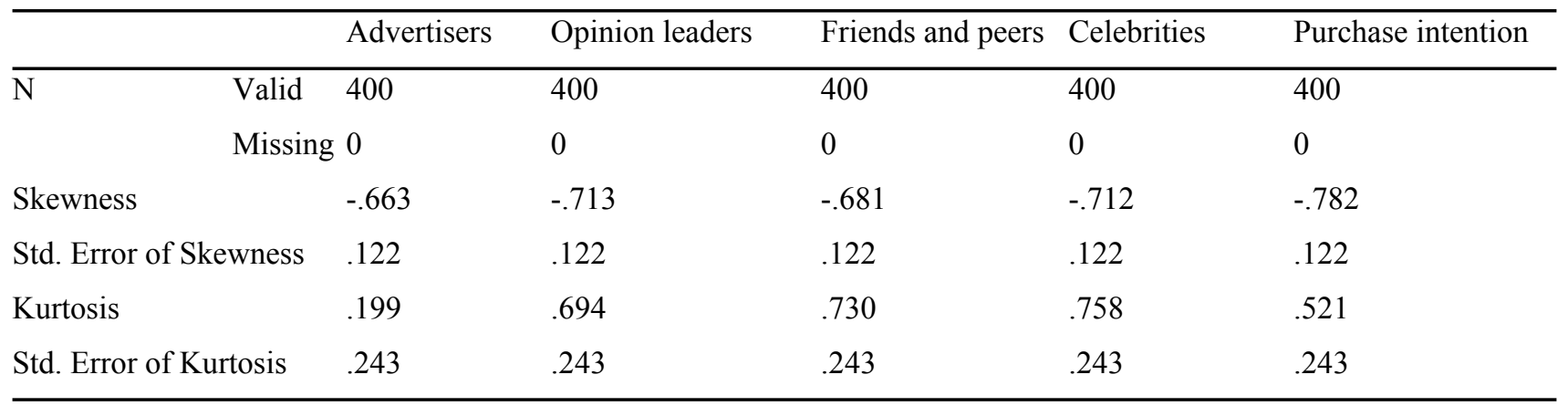


Table 3. Measurement assessment: Outer loadings, Construct reliability and validity

\begin{tabular}{|c|c|c|c|c|c|}
\hline Indicator & Advertisers & Celebrities & Friends and peers & Purchase intention & Opinion leaders \\
\hline Ad1 & 0.983 & & & & \\
\hline $\mathrm{Ad} 2$ & 0.987 & & & & \\
\hline Ad3 & 0.949 & & & & \\
\hline CI1 & & 0.984 & & & \\
\hline $\mathrm{CI} 2$ & & 0.976 & & & \\
\hline $\mathrm{CI} 3$ & & 0.980 & & & \\
\hline CI4 & & 0.965 & & & \\
\hline CI5 & & 0.980 & & & \\
\hline Fr1 & & & 0.973 & & \\
\hline Fr2 & & & 0.970 & & \\
\hline Fr3 & & & 0.981 & & \\
\hline Fr4 & & & 0.968 & & \\
\hline PI1 & & & & 0.964 & \\
\hline PI2 & & & & 0.983 & \\
\hline PI3 & & & & 0.977 & \\
\hline PI4 & & & & 0.980 & \\
\hline OL1 & & & & & 0.984 \\
\hline OL2 & & & & & 0.977 \\
\hline OL3 & & & & & 0.962 \\
\hline AVE & 0.947 & 0.954 & 0.946 & 0.953 & 0.949 \\
\hline CR & 0.982 & 0.991 & 0.986 & 0.988 & 0.982 \\
\hline Cronbach's & 0.972 & 0.988 & 0.981 & 0.983 & 0.973 \\
\hline Alpha & & & & & \\
\hline
\end{tabular}


Table 4. Discriminant validity: Heterotrait-Monotrait (HTMT) Ratio

\begin{tabular}{llllll}
\hline & 1 & 2 & 3 & 4 & 5 \\
\hline 1 Advertisers & $\mathbf{0 . 9 7 3}$ & & & & \\
2 Celebrities & 0.409 & $\mathbf{0 . 9 7 7}$ & & & \\
3 Friends and peers & 0.481 & 0.454 & $\mathbf{0 . 9 7 3}$ & & \\
4 Opinion leaders & 0.519 & 0.498 & 0.374 & $\mathbf{0 . 9 7 4}$ & \\
5 Purchase intention & 0.462 & 0.523 & 0.615 & 0.462 & $\mathbf{0 . 9 7 6}$ \\
\hline
\end{tabular}

Note: The diagonal displays the square root of the average variance extracted (AVE) in bold.

Table 5. Results of algorithm and bootstrapping tests

\begin{tabular}{lcccccc}
\hline & Coefficients & Mean & $\begin{array}{c}\text { Standard } \\
\text { Deviation }\end{array}$ & $\begin{array}{c}\mathrm{T} \\
\text { Statistics }\end{array}$ & $\begin{array}{c}\text { P } \\
\text { Values* }\end{array}$ & Support \\
\hline Advertisers -> Purchase intention & 0.098 & 0.096 & 0.054 & 1.855 & 0.064 & No \\
$\begin{array}{l}\text { Celebrities -> Purchase intention } \\
\text { Friends and peers -> Purchase }\end{array}$ & 0.223 & 0.224 & 0.054 & 4.058 & 0.000 & Yes \\
$\begin{array}{l}\text { intention } \\
\text { Opinion leaders -> Purchase }\end{array}$ & 0.407 & 0.407 & 0.054 & 7.539 & 0.000 & Yes \\
intention & 0.146 & 0.145 & 0.052 & 2.760 & 0.006 & Yes \\
& & & & & & \\
Model Fit Summary: SRMR = 0.025, Chi-Square $=1,310.111, \mathrm{NFI}=0.912, \mathrm{R}^{2}$ (Purchase intention) $=0.472$ & \\
\hline
\end{tabular}

Note: ${ }^{*} p<0.05$ (two-tailed) 